Check for updates

Cite this: RSC Adv., 2018, 8, 2708

Received 20th November 2017

Accepted 5th January 2018

DOI: 10.1039/c7ra12628j

rsc.li/rsc-advances

\section{Synthesis of manganese phosphate hybrid nanoflowers by collagen-templated biomineralization $\uparrow$}

\author{
Jean Claude Munyemana, Huixia He, Shenglong Ding, Jie Yin, Pinxian Xi (D) \\ and Jianxi Xiao (D)*
}

Construction of protein-inorganic hybrid materials with hierarchical nanostructures is critical for the creation of advanced multi-functional materials. We herein for the first time report the synthesis of protein-manganese phosphate hybrid nanomaterials by environmentally amiable biomineralization approach. We have demonstrated that collagen provides an excellent biotemplate to modulate the morphology of the hybrid materials, leading to exquisite nanoflowers with branched petals. In this timedependent biomineralization process, collagen played an essential role in the production of proteinmanganese phosphate hybrid materials by inducing the nucleation of manganese phosphates to form a scaffold as well as serving as a glue to hold the petals together. The as-prepared $\mathrm{CL}-\mathrm{Mn}_{3}\left(\mathrm{PO} \mathrm{O}_{2}\right)_{2}$ nanoflowers exhibited good catalytic activity towards water oxidation. The unique $(G l y-X-Y)_{n}$ amino acid sequences and triple helix structure may provide extraordinary capability for collagen to create hybrid nanomaterials via collagen-templated biomineralization. The single-size and high purity may endow recombinant collagen as a powerful strategy to establish superior biotemplates. This facile and green approach to produce collagen-manganese phosphate hybrid nanoflowers greatly advances our capability to construct manganese phosphates-based functional materials.

\section{Introduction}

Construction of protein-inorganic hybrid materials with hierarchical nanostructures plays a fundamental role in the development of improved functional materials. ${ }^{1-3}$ The mutual interaction and complementarity of biological molecules and inorganic materials synergetically reinforces the functionality of these hybrid materials. ${ }^{4}$ It remains a major challenge to create hybrid materials with exquisitely mediated hierarchical structures. Biomineralization is a classical process widely used by nature to produce proteininorganic materials with exceptional functionality and delicate morphology, including bones and teeth as typical examples. $^{5-8}$ Proteins serve as excellent bio-templates to control the nucleation and growth of inorganic materials in living organisms. Inspired by nature, protein-based biomineralization has been extensively explored to generate a variety of inorganic nanomaterials such as calcium carbonate and calcium phosphate. ${ }^{9-15}$

State Key Laboratory of Applied Organic Chemistry, Key Laboratory of Nonferrous Metal Chemistry and Resources Utilization of Gansu Province, College of Chemistry and Chemical Engineering, Lanzhou University, Lanzhou 730000, P. R. China. E-mail:xiaojx@lzu.edu.cn

$\dagger$ Electronic supplementary information (ESI) available: Fig. S1 and S2. See DOI: $10.1039 / \mathrm{c} 7 \mathrm{ra} 12628 \mathrm{j}$
Transition metal phosphates have been widely investigated due to their superior redox properties with promising applications in heterogeneous catalysis. They have been explored as cathode electrode materials in lithium batteries considering their low cost, environmentally friendly nature and large theoretical specific capacity. ${ }^{16}$ Owing to the relatively high specific area, transition metal phosphates have been applied as adsorbents for radionuclide materials and heavy metals. ${ }^{18}$ Numerous phosphate materials with outstanding catalytic features have been generated till date, including zirconium, titanium, vanadium, nickel, iron, chromium, zinc, yttrium, tantalum and niobium phosphates. ${ }^{17,19-26}$

Manganese phosphates are present as switzerite in nature, and have attracted special attention due to their outstanding electrochemical properties. ${ }^{27-30}$ In nature, the water oxidation catalyst of photosynthesis was composed of earth-abundant elements such as $\mathrm{Mn}$ and $\mathrm{Ca}$ in the form of cubical $\mathrm{CaMn}_{4} \mathrm{O}_{5}$ clusters, which functioned under neutral conditions with very low overpotential value. ${ }^{31}$ The unique capability of natural system has inspired the design of manganese phosphate as water oxidation catalyst with superior catalytic performance at neutral $\mathrm{pH}^{32}$ Manganese phosphates have also been applied as oxidation catalysts for methyl mandelate and adonitol, and they played a major role in corrosion protection in mild steels. ${ }^{30,33}$ Various template-free and organically-templated approaches have been developed to create a number of manganese 
phosphates. ${ }^{34,35}$ For example, piperazine and ethylenediamine have been established as organic templates to produce manganese phosphates using hydrothermal methods. ${ }^{34,35}$

Collagen is the most abundant protein in human body, and it is the major component of bone, skin and tendon. ${ }^{36}$ Unlike globular proteins, collagen possesses a distinct triple helical conformation and repetitive $(\mathrm{Gly}-\mathrm{X}-\mathrm{Y})_{n}$ amino acid sequences. ${ }^{37,38}$ The rod-like structure of collagen endows it as an excellent building block for nanodevices, and its superior biological features such as multiple interactions with cell receptors and minimal immunogenicity lead to broad biomedical applications. ${ }^{39,40}$ Compared with animal-derived collagen, recombinant collagen can be generated of uniform size, high purity, superior solubility and zero risk of infectious diseases. $^{\mathbf{4 1}}$ Therefore, recombinant collagen has obtained increasing attention in the construction of various biomaterials.

Collagen has been utilized by human body as the main biological template to produce hydroxyapatite with wellcontrolled hierarchical structures, offering the collagenhydroxyapatite hybrid materials unique structural, mechanical and biochemical properties. ${ }^{42}$ Protein-inorganic nanoflowers have drawn huge interests due to their remarkable features such as large surface areas, high porosity, and active surface functional groups with enhanced functionality. ${ }^{\mathbf{4 3 3 - 4 5}}$ We herein for the first time report the synthesis of protein-manganese phosphate hybrid nanomaterials. We have demonstrated that collagen provides an excellent biotemplate to modulate the morphology of the hybrid materials, leading to well-defined nanoflowers with branched petals.

\section{Experimental section}

\section{Preparation of recombinant collagen $\mathrm{CL}$}

Protein V-CL was expressed in E. coli BL21 strain as previously reported. ${ }^{37,46}$ Briefly, $50 \mathrm{~mL}$ overnight culture was transferred into $1000 \mathrm{~mL} \mathrm{LB}$ medium containing ampicillin $\left(50 \mu \mathrm{g} \mathrm{mL} \mathrm{m}^{-1}\right)$, and was grown at $37{ }^{\circ} \mathrm{C}$ until optical density (OD) at $600 \mathrm{~nm}$ reaching 0.8 . Protein expression was induced by $1 \mathrm{mM}$ isopropyl beta-D-thiogalactopyranoside (IPTG) at $25{ }^{\circ} \mathrm{C}$. Cells were collected after overnight incubation and re-suspended in $50 \mathrm{~mL}$ binding buffer $\left(20 \mathrm{mM} \mathrm{NaH}{ }_{2} \mathrm{PO}_{4}, 500 \mathrm{mM} \mathrm{NaCl}, 50 \mathrm{mM}\right.$ imidazole, $\mathrm{pH}$ 7.4). Cells were disrupted by sonication, and cell debris was removed. The collected supernatants were loaded into a Ni-NTA-Sepharose column, and were eluted using the binding buffer supplemented with $500 \mathrm{mM}$ imidazole. The collected V-CL protein were immediately dialyzed against $50 \mathrm{mM}$ glycine buffer, $\mathrm{pH}$ 8.6. The protein purity was confirmed by the presence of a single band on SDS-PAGE. The $\mathrm{V}$ domain was removed from the purified V-CL by the treatment with trypsin at $28{ }^{\circ} \mathrm{C}$ for $24 \mathrm{~h}$. The reaction was stopped by adding $1 \mathrm{mM}$ phenylmethanesulfonyl fluoride (PMSF). After dialysis against $50 \mathrm{mM}$ Tris buffer $(\mathrm{pH}$ 7.4), recombinant collagen $\mathrm{CL}$ was collected, and its purity was confirmed by SDS-PAGE. The purified CL was then lyophilized and stored at $4{ }^{\circ} \mathrm{C}$ for future use.

\section{Synthesis of collagen-manganese phosphate hybrid nanoflowers}

Different concentrations of CL protein were prepared in PBS buffer (20 mM, pH 7.4). $1 \mathrm{~mL}$ of CL solution was added to $1 \mathrm{~mL}$ $\mathrm{MnCl}_{2}$ solution (3.6 mM). The mixture was stirred for at least $10 \mathrm{~min}$ and then incubated at $25{ }^{\circ} \mathrm{C}$ for $24 \mathrm{~h}$. The precipitates were collected by centrifugation, and washed by ethanol 3 times. The products were air dried at $25{ }^{\circ} \mathrm{C}$. To study the effect of collagen on the morphology, the concentration of CL was varied from 0 to $0.2 \mathrm{wt} \%$, while [Mn(II)] was set as $1.8 \mathrm{mM}$.

\section{Characterization of collagen-manganese phosphate hybrid nanoflowers}

SEM measurements were performed on a Hitachi S-4800 field emission scanning electron microscope (Hitachi limited, Japan) with an operating voltage of $5.0 \mathrm{kV}$. X-ray diffraction (XRD) patterns were recorded on a Rigaku D/ma-2500 diffractometer with $\mathrm{Cu} \mathrm{K} \alpha$ radiation $(40 \mathrm{kV}, 200 \mathrm{~mA})$ at a scanning rate of $0.02^{\circ} \mathrm{s}^{-1}$ in the $2 \theta$ range from 20 to $80^{\circ}$. X-ray photoelectron spectroscopy (XPS) measurements were carried out on a Kratos Axis Ultra ${ }^{\text {DLD }}$ $\mathrm{X}$-ray photoelectron spectrometer (England) with a monochrome X-ray source using $\mathrm{Al} \mathrm{K} \alpha(1486.6 \mathrm{eV})$ radiation. The binding energies measured by XPS were corrected by referencing the $\mathrm{C} 1 \mathrm{~s}$ line to $284.5 \mathrm{eV}$. TEM and electron diffraction (EDX) measurements were recorded using a JEM-2100 transmission electron microscope (JEOL, Japan) at $200 \mathrm{kV}$. Fouriertransform infrared (FT-IR) spectra were obtained using a Nicolet NEXUS 670 infrared spectrometer. Thermogravimetric analysis (TGA) was performed on a TGA/NETZSCH STA449F3 instrument under a nitrogen atmosphere, employing a heating rate of $10{ }^{\circ} \mathrm{C} \min ^{-1}$ from $25{ }^{\circ} \mathrm{C}$ to $500{ }^{\circ} \mathrm{C}$.

\section{Electrochemical measurements}

The catalytic activity of $\mathrm{CL}-\mathrm{Mn}_{3}\left(\mathrm{PO}_{4}\right)_{2}$ hybrid nanomaterials was investigated by cyclic voltammetry $(\mathrm{CV}) .5 \mathrm{mg}$ of synthesized hybrid nanomaterials were dispersed in $1 \mathrm{~mL}$ water with $100 \mu \mathrm{L}$ neutralized Nafion solution. The mixture was then sonicated for at least $20 \mathrm{~min}$ to make a homogeneous solution. $50 \mu \mathrm{L}$ mixture was dropped onto the FTO substrate, which was then dried in $80{ }^{\circ} \mathrm{C}$ oven overnight as working electrode. Before recording electrochemical data, the working electrode was cycled at least 3 times (potential: from 0.7 to $1.5 \mathrm{~V}$; scan rate: $10 \mathrm{mV} \mathrm{s}^{-1}$ ) for getting the smooth curves. The CV measurements were performed under a three-electrode electrochemical cell system at ambient temperature. A BASi $\mathrm{Ag} / \mathrm{AgCl} / 3 \mathrm{M} \mathrm{NaCl}$ reference electrode and a $\mathrm{Pt}$ foil were used as a reference electrode and a counter electrode, respectively. The electrolyte was phosphate buffer with $500 \mathrm{mM}$ buffer strength under $\mathrm{pH}$ 7.0.

\section{Results and discussion}

\section{Synthesis and characterization of collagen-manganese phosphate hybrid nanoflowers}

Collagen protein CL (MW: $22.8 \mathrm{kDa}$ ) was prepared using the high expression cold-shock vector system as previously described, and its purity was confirmed by SDS-PAGE. ${ }^{37}$ The 
collagen-manganese phosphate hybrid nanomaterials CL$\mathrm{Mn}_{3}\left(\mathrm{PO}_{4}\right)_{2}$ were prepared by incubating the mixture of $1.8 \mathrm{mM}$ aqueous solution of $\mathrm{Mn}\left(\mathrm{NO}_{3}\right)_{2}$ and $0.2 \mathrm{wt} \%$ of CL protein in $20 \mathrm{mM}$ PBS buffer at $25{ }^{\circ} \mathrm{C}$ for $24 \mathrm{~h}$. X-ray diffraction (XRD) and $\mathrm{X}$-ray photoelectron spectroscopy (XPS) techniques were used to characterize the as-prepared products (Fig. 1). The XRD pattern of the synthesized nanomaterials fitted well with that of hydrated manganese phosphate $\mathrm{Mn}_{3}\left(\mathrm{PO}_{4}\right)_{2} \cdot 3 \mathrm{H}_{2} \mathrm{O}$ (JCPDS no. 3426) (Fig. 1a). The XPS spectra of the nanomaterials displayed the composition of $\mathrm{Mn}, \mathrm{P}, \mathrm{O}, \mathrm{N}$ and $\mathrm{C}$ elements, confirming the presence of collagen and $\mathrm{Mn}_{3}\left(\mathrm{PO}_{4}\right)_{2}$ (Fig. 1b).

FT-IR spectra of the as-prepared hybrid nanomaterials were also acquired (Fig. S1 $\dagger$ ). The observed vibration peaks corresponding to the $\mathrm{N}-\mathrm{H}, \mathrm{C}-\mathrm{H}, \mathrm{C}=\mathrm{O}$ and $\mathrm{NH}_{2}$ bonds further confirmed the presence of collagen within the synthesized collagen-manganese phosphate hybrid nanomaterials $\mathrm{CL}_{-}$ $\mathrm{Mn}_{3}\left(\mathrm{PO}_{4}\right)_{2}$. The content of collagen CL in the hybrid nanomaterials was further evaluated by thermogravimetric analysis (TGA) (Fig. S2 $\dagger$ ). TGA plots showed two weight-loss stages, which corresponded to the loss of absorbed water (below $200{ }^{\circ} \mathrm{C}$ ) and the thermal decomposition of collagen $\left(200-500{ }^{\circ} \mathrm{C}\right)$, respectively. All the results indicated that a significant amount of collagen was embedded within the hybrid nanomaterials.

The morphology of the CL- $\mathrm{Mn}_{3}\left(\mathrm{PO}_{4}\right)_{2}$ hybrid nanomaterials was examined by field-emission scanning electron microscopy (FESEM) and transmission electron microscopy (TEM) techniques (Fig. 2). The SEM images showed flower-shaped nanostructures consisting of well-organized petals (Fig. 2a). A closer
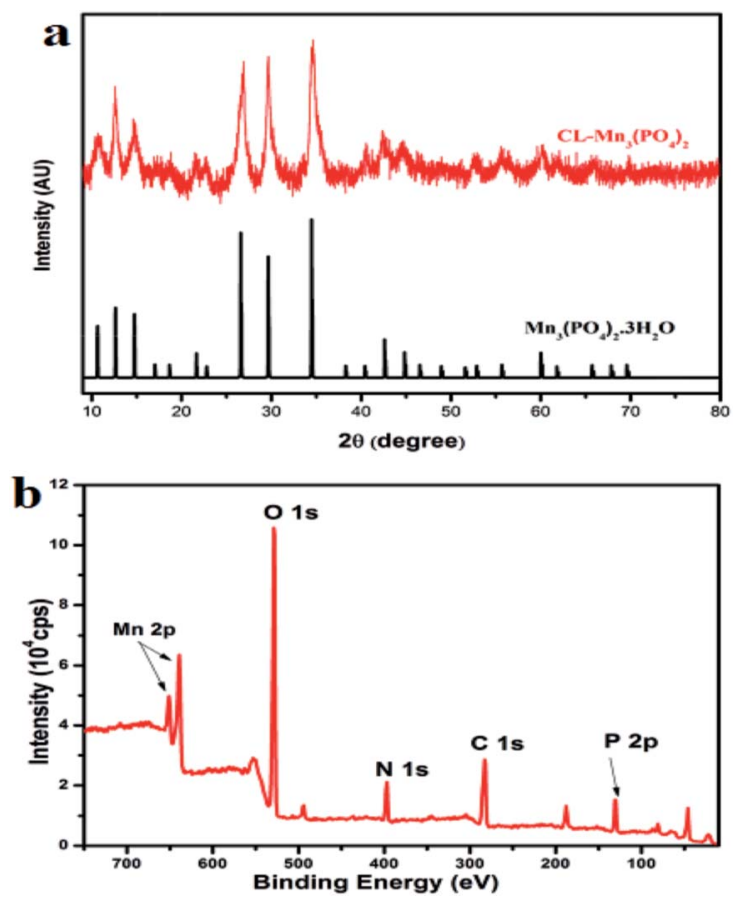

Fig. 1 XRD and XPS characterization of $C L-M n_{3}\left(P O_{4}\right)_{2}$ hybrid nanomaterials. (a) XRD patterns of $\mathrm{CL}-\mathrm{Mn}_{3}\left(\mathrm{PO}_{4}\right)_{2}$ hybrid nanomaterials (red) and a standard manganese phosphate hydrate $\mathrm{Mn}_{3}\left(\mathrm{PO}_{4}\right)_{2} \cdot 3 \mathrm{H}_{2} \mathrm{O}$ (JCPDS no. 3-426) (black). (b) XPS spectra of the $\mathrm{CL}-\mathrm{Mn}_{3}\left(\mathrm{PO}_{4}\right)_{2}$ nanomaterials.
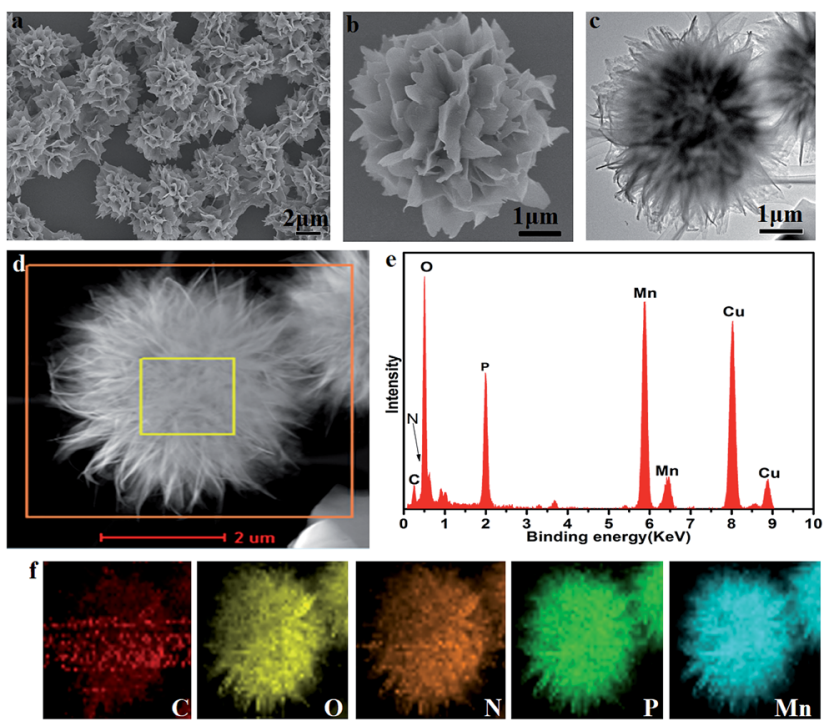

Fig. 2 FESEM images of the obtained $C L-M n_{3}\left(P_{4}\right)_{2}$ nanomaterials (a and b); TEM image (c) and HAADF-STEM image (d) of the same hybrid nanomaterials; EDX spectrum of the synthesized nanomaterials (e); EDS mapping images of $\mathrm{C}, \mathrm{O}, \mathrm{N}, \mathrm{P}$, and $\mathrm{Mn}$ for the square region of the particles in (d and f).

observation of a single nanoflower showed clear hierarchical arrangements of the petals (Fig. 2b). TEM images indicated that the $\mathrm{CL}-\mathrm{Mn}_{3}\left(\mathrm{PO}_{4}\right)_{2}$ hybrid nanoflowers were self-assembled through an oriented growth (Fig. 2c). The high-angle annular dark-field scanning TEM (HAADF-STEM) image suggested that the primary manganese phosphate nanoparticles gradually aggregate to form nanoflowers with hierarchical structures (Fig. 2d). Energy dispersive X-ray (EDX) analysis further confirmed the presence of $\mathrm{C}, \mathrm{N}, \mathrm{O}, \mathrm{P}$ and $\mathrm{Mn}$ elements in the hybrid nanomaterials and the corresponding elemental mapping results by energy dispersive X-ray spectroscopy (EDS) showed that all the elements were distributed homogeneously on the particles, demonstrating the encapsulation of collagen in the synthesized nanoflowers (Fig. 2e and f). All the results demonstrated that the $\mathrm{CL}-\mathrm{Mn}_{3}\left(\mathrm{PO}_{4}\right)_{2}$ hybrid particles formed well-defined flower-like supramolecular structures. This is the first report of protein-templated biomineralization that has been successfully utilized to generate $\mathrm{Mn}_{3}\left(\mathrm{PO}_{4}\right)_{2}$ nanomaterials.

\section{The critical role of collagen in hybrid nanoflowers}

In order to evaluate the critical role of collagen in the production of hybrid nanoflowers, the morphologies of CL- $\mathrm{Mn}_{3}\left(\mathrm{PO}_{4}\right)_{2}$ nanomaterials were characterized under a range of collagen concentrations from 0 to $0.2 \mathrm{wt} \%$ while keeping a constant $\mathrm{Mn}$ (II) concentration (1.8 mM) (Fig. 3). In the absence of any collagen, manganese phosphate aggregates did not display wellordered structure (Fig. 3a). When the collagen concentration was increased, petals became evident, and they tended to get together to form a flower bouquet. The addition of $0.2 \mathrm{wt} \%$ of collagen resulted in well-defined branched nanoflowers (Fig. 3b-d). The clear dependence of the morphologies of CL$\mathrm{Mn}_{3}\left(\mathrm{PO}_{4}\right)_{2}$ on the concentration of $\mathrm{CL}$ indicated that collagen 

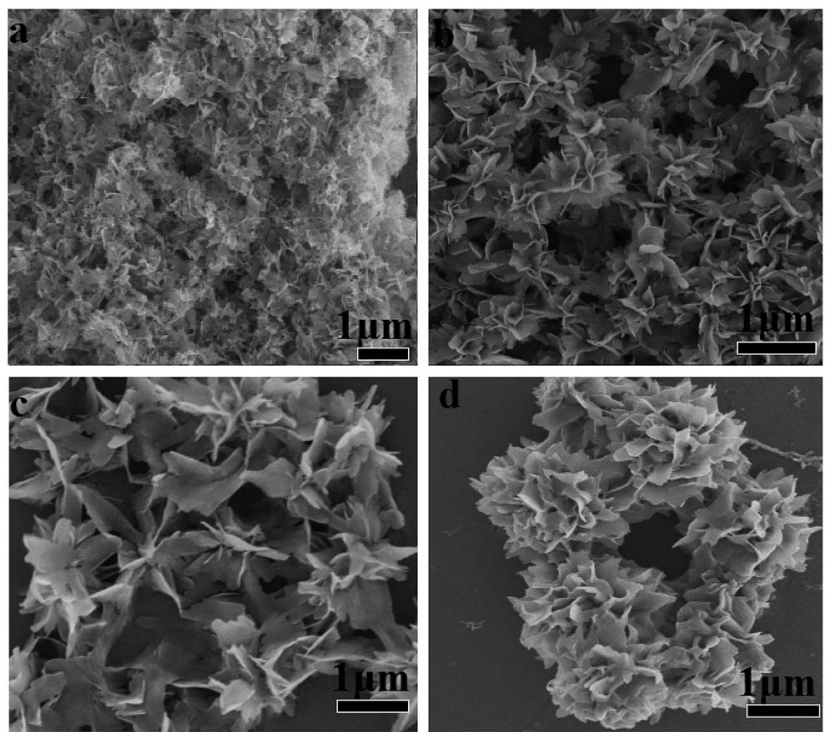

Fig. 3 SEM images of the $\mathrm{CL}-\mathrm{Mn}_{3}\left(\mathrm{PO}_{4}\right)_{2}$ hybrid nanomaterials obtained after $24 \mathrm{~h}$ incubation at $25^{\circ} \mathrm{C}$ using a constant concentration of $\mathrm{MnCl}_{2}(1.8 \mathrm{mM})$ and various concentrations of collagen: $0 \mathrm{wt} \%(\mathrm{a})$, $0.01 \mathrm{wt} \%$ (b), $0.05 \mathrm{wt} \%$ (c) and $0.2 \mathrm{wt} \%$ (d).

could conveniently mediate the nanostructures of hybrid materials.

The morphologies of CL- $\mathrm{Mn}_{3}\left(\mathrm{PO}_{4}\right)_{2}$ hybrid nanoflowers were further examined after treatments with calcination and glutaraldehyde/EDTA (Fig. 4). Calcination of the synthesized hybrid nanomaterials at $350{ }^{\circ} \mathrm{C}$ for $6 \mathrm{~h}$ led to the loss of flowerlike structures and scattered petals, indicating that collagen played an essential role to maintain the supramolecular structure of (Fig. 4a). When the synthesized nanoflowers were first cross-linked employing glutaraldehyde, and then treated with ethylenediaminetetraacetic acid (EDTA) to remove the $\mathrm{Mn}^{2+}$ ions, they also lost the well-ordered flower-shape, indicating the $\mathrm{Mn}^{2+}$ ions were also the determinant elements for the formation of nanoflowers (Fig. 4b). These results suggested that both collagen and $\mathrm{Mn}^{2+}$ ions were uniformly distributed in the hybrid nanomaterials, and their co-participation finely modulate the flower-like morphology. Collagen likely triggered the nucleation of the manganese phosphate crystals to form a framework for the petals and played as a glue to hold the petals together.
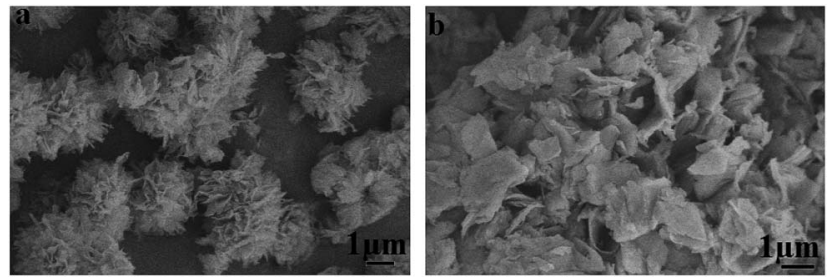

Fig. 4 SEM images of the $\mathrm{CL}-\mathrm{Mn}_{3}\left(\mathrm{PO}_{4}\right)_{2}$ hybrid nanoflowers treated by calcination (a), and glutaraldehyde/EDTA (b). Calcination was performed at $350{ }^{\circ} \mathrm{C}$ for $6 \mathrm{~h}$. The $\mathrm{CL}-\mathrm{Mn}_{3}\left(\mathrm{PO}_{4}\right)_{2}$ hybrid nanoflowers were first treated with glutaraldehyde $(0.8 \mathrm{wt} \%)$ and then EDTA (1 wt\%).
Time-dependent growth of collagen-manganese phosphate hybrid nanoflowers

SEM was used to monitor the time dependent evolution process of CL- $\mathrm{Mn}_{3}\left(\mathrm{PO}_{4}\right)_{2}$ nanoflowers (Fig. 5). Nanoparticles with small petals started to appear after $1 \mathrm{~h}$, and the petals became better organized after $6 \mathrm{~h}$ (Fig. 5a-d). When the incubation time extended to $24 \mathrm{~h}$, the hybrid materials formed well-defined delicate flower-shaped nanostructures with multilayered petals (Fig. 5e and f). These results indicated that it was a timedependent gradual growing process for the hybrid materials to form multi-layered nanoflowers.

\section{The collagen-manganese phosphate hybrid nanoflowers as water oxidation catalysts}

The catalytic capacity of water oxidation of the synthesized CL$\mathrm{Mn}_{3}\left(\mathrm{PO}_{4}\right)_{2}$ hybrid nanoflowers was investigated by cyclic voltammetry (CV) in $0.5 \mathrm{M}$ sodium phosphate electrolyte at $\mathrm{pH} 7.0$ (Fig. 6). The current values were normalized to the catalyst' effective surface area on the working electrode. The current density of CL- $\mathrm{Mn}_{3}\left(\mathrm{PO}_{4}\right)_{2}$ normalized to the surface area was $16 \mathrm{~mA} \mathrm{~cm}$ at the overpotential of $680 \mathrm{mV}$. The Tafel slope obtained from the polarization-corrected $\mathrm{CV}$ curves was
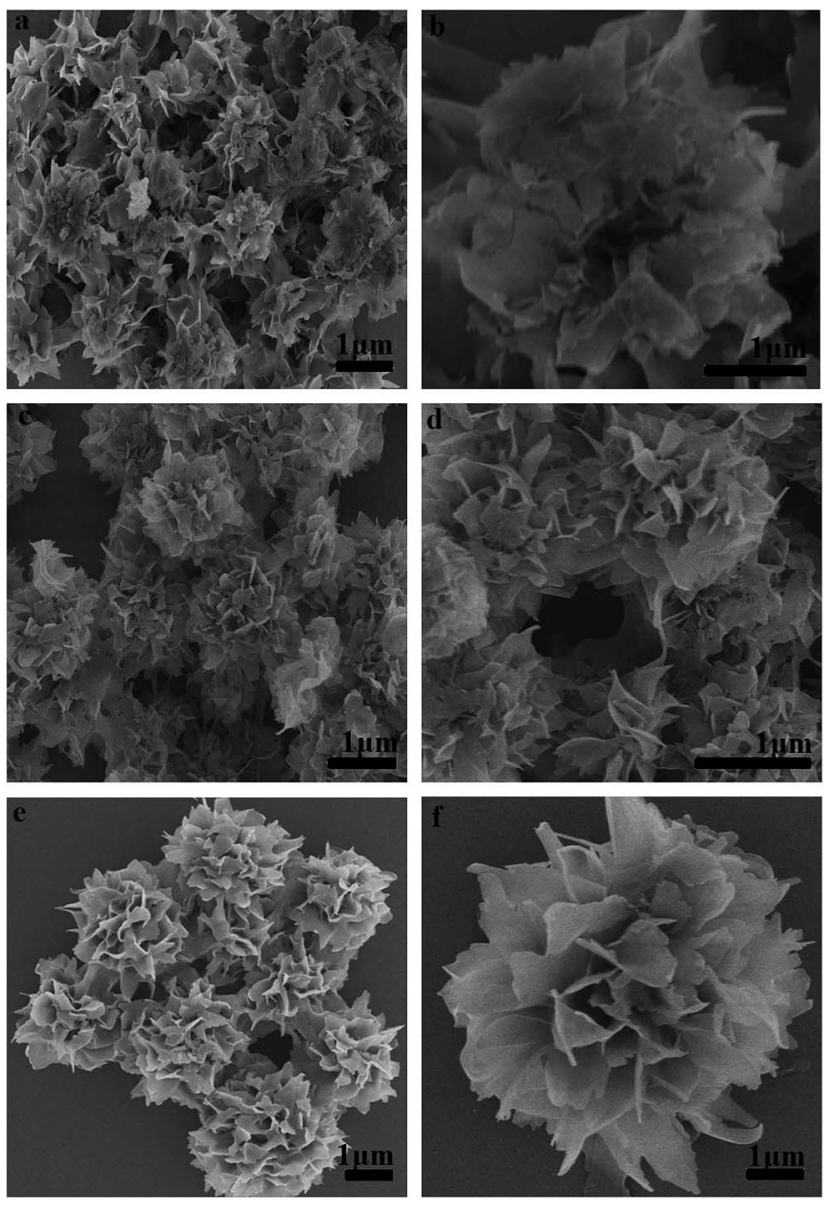

Fig. 5 SEM images of $\mathrm{CL}-\mathrm{Mn}_{3}\left(\mathrm{PO}_{4}\right)_{2}$ hybrid nanomaterials obtained by different incubation time: $1 \mathrm{~h}(\mathrm{a}, \mathrm{b}), 6 \mathrm{~h}(\mathrm{c}, \mathrm{d})$, and $24 \mathrm{~h}(\mathrm{e}, \mathrm{f})$. The mixture of $\mathrm{CL}(0.2 \mathrm{wt} \%)$ and $\mathrm{MnCl}_{2}(1.8 \mathrm{mM})$ were incubated at $25^{\circ} \mathrm{C}$. 


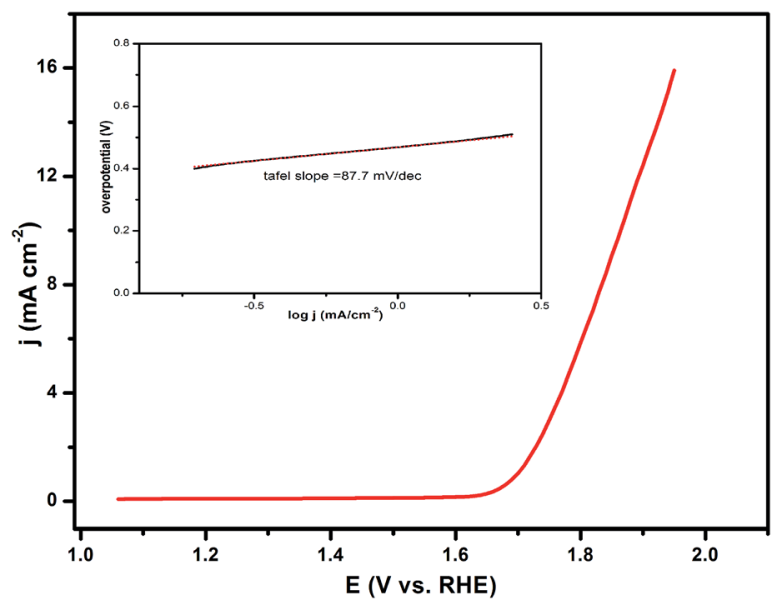

Fig. 6 Electrochemical characterization of $\mathrm{CL}-\mathrm{Mn}_{3}\left(\mathrm{PO}_{4}\right)_{2}$ nanospheres. Polarization-corrected cyclic voltammogram (CV) curves and Tafel plots for $\mathrm{CL}-\mathrm{Mn}_{3}\left(\mathrm{PO}_{4}\right)_{2}$ spin-coated on the FTO substrate. The current value was normalized to the surface area of the catalyst.

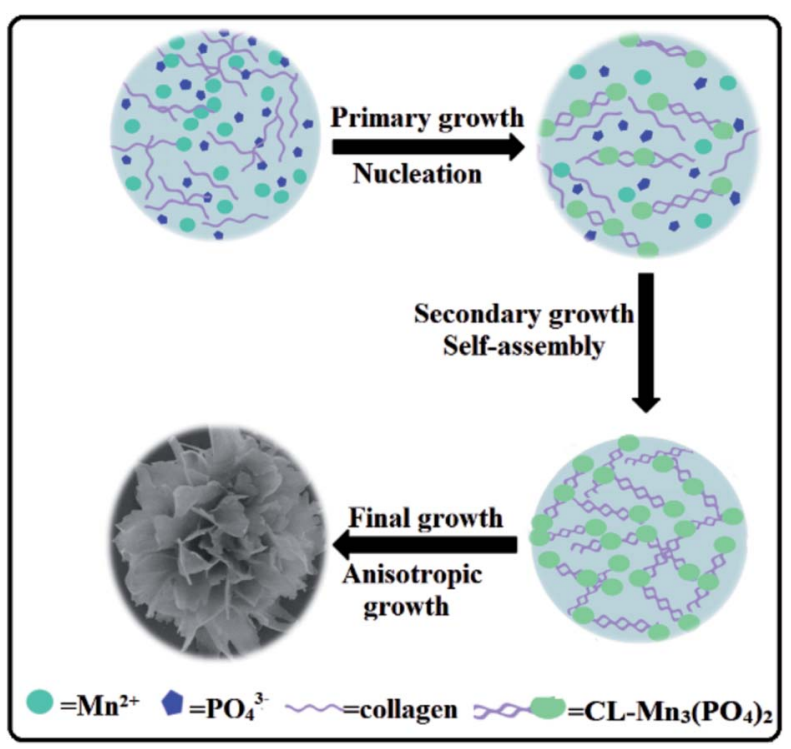

Fig. 7 Schematic illustration of the formation mechanism of $\mathrm{CL}-$ $\mathrm{Mn}_{3}\left(\mathrm{PO}_{4}\right)_{2}$ nanospheres.

$87.8 \mathrm{mV} \mathrm{dec}{ }^{-1}$. All the results indicated that CL- $\mathrm{Mn}_{3}\left(\mathrm{PO}_{4}\right)_{2}$ nanospheres presented a good catalyst for water oxidation, which may be due to the synergistic effect between manganese phosphate and collagen.

\section{Conclusions}

Construction of protein-inorganic hybrid materials with hierarchical nanostructures is critical for the creation of advanced multi-functional materials. ${ }^{2}$ Protein-inorganic nanoflowers have gained growing attention due to their superior features including large surface areas and active surface functional groups. Collagen-templated biomineralization has been selected by nature to generate hierarchical protein-inorganic hybrid nanomaterials for the construction of bone and teeth for human being. We herein for the first time have demonstrated that recombinant collagen provides an excellent biotemplate to generate protein-manganese phosphate hybrid materials with exquisite flower-like nanostructures.

Recombinant collagen contains a large number of charged amino acids, which could promote the interaction of manganese ions and collagen. At the initial primary growth stage, $\mathrm{Mn}$ (III) ions first form a complex with collagen by interaction with charged amino acids distributed along the protein chain, resulting in the formation of primary crystals (Fig. 7). In the secondary growth step, further self-assembly of the manganese phosphate primary crystals leads to the formation of nanoflowers with small petals. Collagen probably covers the surface, and stabilizes the primary nanoparticles. At the final anisotropic growth stage, the nanoparticles continued to assemble into the final well-ordered multi-layered nanoflowers with branched petals. In this time-dependent biomineralization process, collagen played an essential role in the production of protein-manganese phosphate hybrid materials by inducing the nucleation of manganese phosphates to form a scaffold as well as serving as a glue to hold the petals together.

The unique (Gly-X-Y) ${ }_{n}$ amino acid sequences and triple helix structure may provide extraordinary capability for collagen to create hybrid nanomaterials via collagen-templated biomineralization. The single-size and high purity may endow recombinant collagen as a powerful strategy to establish superior biotemplates. The application of these newly constructed CL- $\mathrm{Mn}_{3}\left(\mathrm{PO}_{4}\right)_{2}$ nanomaterials as water oxidation catalysts has demonstrated their excellent functional features. This facile and environmentally amiable biomineralization approach to produce collagen-manganese phosphate hybrid nanoflowers greatly advances our capability to construct manganese phosphates-based functional materials.

\section{Conflicts of interest}

The authors declare no competing conflict of interests.

\section{Acknowledgements}

This work was supported by grants from the National Natural Science Foundation of China (Grant no. 21775059) and the Fundamental Research Funds for the Central Universities (Grant no. lzujbky-2016-k10).

\section{References}

1 S. Lagziel-Simis, N. Cohen-Hadar, H. Moscovich-Dagan, Y. Wine and A. Freeman, Curr. Opin. Biotechnol., 2006, 17, 569-573.

2 M. B. Dickerson, K. H. Sandhage and R. R. Naik, Chem. Rev., 2008, 108, 4935-4978.

3 X. Wang, H. C. Schroder and W. E. Muller, Trends Biotechnol., 2014, 32, 441-447.

4 J. Ge, J. Lei and R. N. Zare, Nat. Nanotechnol., 2012, 7, 428432. 
5 L. Addadi, S. Raz and S. Weiner, Adv. Mater., 2003, 15, 959970.

6 A.-W. Xu, Y. Ma and H. Cölfen, J. Mater. Chem., 2007, 17, 415449.

7 S. Weiner and L. Addadi, J. Mater. Chem., 1997, 7, 689-702.

8 A. Arakaki, K. Shimizu, M. Oda, T. Sakamoto, T. Nishimura and T. Kato, Org. Biomol. Chem., 2015, 13, 974-989.

9 T. Wang, D. Porter and Z. Shao, Adv. Funct. Mater., 2012, 22, 435-441.

10 Y. Cai and J. Yao, Nanoscale, 2010, 2, 1842.

11 R. Kurapati and A. M. Raichur, J. Mater. Chem. B, 2013, 1, 3175.

12 X. Q. Li, Z. Feng, Y. Xia and H. C. Zeng, Chemistry, 2012, 18, 1945-1952.

13 C. Cheng, Z. Shao and F. Vollrath, Adv. Funct. Mater., 2008, 18, 2172-2179.

14 Z. Ding, H. Han, Z. Fan, H. Lu, Y. Sang, Y. Yao, Q. Cheng, Q. Lu and D. L. Kaplan, ACS Appl. Mater. Interfaces, 2017, 9, 16913-16921.

15 T. Kato, A. Sugawara and N. Hosoda, Adv. Mater., 2002, 14, 869.

16 A. K. Padhi, K. S. Nanjundaswamy, C. Masquelier, S. Okada and J. B. Goodenough, J. Electrochem. Soc., 1997, 144, 1609.

17 X. Tian, W. He, J. Cui, X. Zhang, W. Zhou, S. Yan, X. Sun, X. Han, S. Han and Y. Yue, J. Colloid Interface Sci., 2010, 343, 344-349.

18 A. Dutta, A. K. Patra and A. Bhaumik, Microporous Mesoporous Mater., 2012, 155, 208-214.

19 J. Jiménez-Jiménez, P. Maireles-Torres, P. Olivera-Pastor, E. Rodríguez-Castellón, A. Jiménez-López, D. J. Jones and J. Rozière, Adv. Mater., 1998, 10, 812-815.

20 A. Bhaumik and S. Inagaki, J. Am. Chem. Soc., 2001, 123, 691696.

21 J. Yu, A. Wang, J. Tan, X. Li, J. A. van Bokhoven and Y. Hu, J. Mater. Chem., 2008, 18, 3601.

22 U. R. Pillai and E. Sahle-Demessie, Chem. Commun., 2004, 826-827, DOI: 10.1039/b313747c.

23 A. Tarafdar, S. Biswas, N. K. Pramanik and P. Pramanik, Microporous Mesoporous Mater., 2006, 89, 204-208.

24 W. He, S. Yan, Y. Wang, X. Zhang, W. Zhou, X. Tian, X. Sun and X. Han, J. Alloys Compd., 2009, 477, 657-660.

25 Q. Luo, S. Shen, G. Lu, X. Xiao, D. Mao and Y. Wang, J. Mater. Chem., 2009, 19, 8079.
26 Y. Zhang, J. Wang, J. Ren, X. Liu, X. Li, Y. Xia, G. Lu and Y. Wang, Catal. Sci. Technol., 2012, 2, 2485.

27 S. Fernández, J. L. Pizarro, J. L. Mesa, L. Lezama, M. I. Arriortua, R. Olazcuaga and T. Rojo, Inorg. Chem., 2001, 40, 3476-3483.

28 K. Jin, J. Park, J. Lee, K. D. Yang, G. K. Pradhan, U. Sim, D. Jeong, H. L. Jang, S. Park, D. Kim, N.-E. Sung, S. H. Kim, S. Han and K. T. Nam, J. Am. Chem. Soc., 2014, 136, 7435-7443.

29 S. Ferdov, A. M. L. Lopes, Z. Lin and R. A. S. Ferreira, Chem. Mater., 2007, 19, 6025-6029.

30 F. Ben Brahim and H. Boughzala, J. Mol. Struct., 2013, 1034, 336-345.

31 J. Barber, Chem. Soc. Rev., 2009, 38, 185-196.

32 X. Shen, Q. Wang, Y. Liu, W. Xue, L. Ma, S. Feng, M. Wan, F. Wang and C. Mao, Sci. Rep., 2016, 6, 28989.

33 A. G. Fadnis and S. K. Kulshrestha, React. Kinet. Catal. Lett., 1982, 19, 267-269.

34 K. O. Kongshaug, H. Fjellvåg and K. P. Lillerud, J. Solid State Chem., 2001, 156, 32-36.

35 J. Escobal, J. L. Pizarro, J. L. Mesa, L. Lezama, R. Olazcuaga, M. I. Arriortua and T. Rojo, Chem. Mater., 2000, 12, 376-382.

36 M. D. Shoulders and R. T. Raines, Annu. Rev. Biochem., 2009, 78, 929-958.

37 A. Yoshizumi, Z. Yu, T. Silva, G. Thiagarajan, J. A. Ramshaw, M. Inouye and B. Brodsky, Protein Sci., 2009, 18, 1241-1251.

38 Y. Xu, D. R. Keene, J. M. Bujnicki, M. Hook and S. Lukomski, J. Biol. Chem., 2002, 277, 27312-27318.

39 Y. Li and S. M. Yu, Curr. Opin. Chem. Biol., 2013, 17, 968-975. 40 M. He, L. Wang, J. Wu and J. Xiao, Chem.-Eur. J., 2016, 22, 1914-1917.

41 Y. Y. Peng, L. Howell, V. Stoichevska, J. A. Werkmeister, G. J. Dumsday and J. A. M. Ramshaw, Microb. Cell Fact., 2012, 11, 146.

42 E. A. Zimmermann and R. O. Ritchie, Adv. Healthcare Mater., 2015, 4, 1287-1304.

43 M. Li, M. Luo, F. Li, W. Wang, K. Liu, Q. Liu, Y. Wang, Z. Lu and D. Wang, J. Phys. Chem. C, 2016, 120, 17348-17356.

44 P. Koley, M. Sakurai and M. Aono, ACS Appl. Mater. Interfaces, 2016, 8, 2380-2392.

45 B. Zhang, P. Li, H. Zhang, L. Fan, H. Wang, X. Li, L. Tian, N. Ali, Z. Ali and Q. Zhang, RSC Adv., 2016, 6, 46702-46710. 46 B. An, V. Abbonante, S. Yigit, A. Balduini, D. L. Kaplan and B. Brodsky, J. Biol. Chem., 2013, 289, 4941-4951. 